\title{
The Outcomes of Late Term Surgical Treatment of Penetrating Peripheral Nerve Injuries
}

\author{
Yurdal GEZERCAN', Güner MENEKŞE² , Ali İhsan ÖKTEN', Ali ARSLAN¹, Kerem Mazhar ÖZSOY³, Tuncay ATEŞ ${ }^{1}$, \\ Mustafa ÇIKILI' ${ }^{1}$ İsmail UYSAL ${ }^{1}$, Burak OLMAZ1 ${ }^{1}$, Aslan GÜZEL ${ }^{4}$
}

${ }^{1}$ Adana Numune Training and Research Hospital, Department of Neurosurgery, Adana, Turkey

${ }^{2}$ Ankara Training and Research Hospital, Department of Neurosurgery, Ankara, Turkey

${ }^{3}$ Çukurova University, School of Medicine, Department of Neurosurgery, Adana, Turkey

${ }^{4}$ Bahçeşehir University, School of Medicine, Department of Neurosurgery, İstanbul, Turkey

\section{ABSTRACT}

AIM: The aim of this retrospective study was to evaluate the follow-up results of patients who received late-term surgical treatment for peripheral nerve lesions caused by penetrating injuries.

MATERIAL and METHODS: The study included 25 patients who underwent surgery for peripheral nerve injuries in our clinic between 2007 and 2013. The patients were evaluated with respect to age, gender, etiology of the trauma, the affected nerve, clinical examinations, electrophysiological findings, surgical techniques and functional outcomes.

RESULTS: The study included 30 nerves of 25 patients (19 male, 6 female; mean age 30.1 years). The mean time between the initial injury and admission to our clinic was 11.5 months (range, 3 to 30 months). Cuts caused by glass were the most common cause of injury (68.5\%). The most commonly injured nerves in our patients were the median nerve (43.4\%) and ulnar nerve (26.6\%). External neurolysis and decompression were performed in eleven patients, epineurotomy and internal neurolysis were performed in eight patients, epineural repair was performed in fourteen patients, fascicular repair was performed in three patients, and interfascicular anastomosis using sural nerve grafting was performed in five patients. Postoperative motor strength and electrophysiological analyses showed significant improvements. Better outcomes were obtained in cases with median nerve injuries rather than other nerve injuries. Additionally, patients undergoing external neurolysis and decompression exhibited better outcomes than those undergoing other surgical approaches.

CONCLUSION: Although surgical treatment is recommended as early as possible for peripheral nerve injuries, late-term surgical treatments may provide positive outcomes.

KEYWORDS: Nerve repair, penetrating injury, peripheral nerve injury, surgical method, trauma

\section{INTRODUCTION}

Peripheral nerve injury (PNI) is still a significant cause of morbidity and disability throughout the world. Physical trauma, including traffic accidents and injuries due to sharp and penetrating objects such as broken glass, gunshots, falls and fractures, is the most common cause of $\mathrm{PNI}$
In previous studies, the incidence of PNI has been reported to be 13 to 23 per 100000 individuals per year. PNIs have been estimated to affect between $1.64 \%$ and $2.8 \%$ of all trauma patients $(24,31)$. $\mathrm{PNI}$ is a common problem, especially in young adult men, and may cause serious disability in this productive age group unless the injured nerve is repaired (1, 22, 24). 
Some partial peripheral nerve lesions can improve spontaneously without surgery. On the other hand, many complete nerve lesions caused by lacerations or penetrating injuries do not improve spontaneously over time. Therefore, these cases become candidates for surgical treatment.

Improved microsurgical techniques utilizing neurophysiological studies, the evaluation of the outcomes, and more objective methods increase the possibility of successful repair of nerve injuries (19). Many studies have reported outcomes after repair of peripheral nerve injuries, but there is no agreement regarding the timing of late-term surgery. However, Rochkind et al suggested that injured peripheral nerves survive for an extended period of time, and microsurgical treatment can result in functional improvements in these patients $(26,27)$.

This study aimed to evaluate the surgical techniques and preand postoperative clinical and electrophysiological changes in penetrating and cutting injuries of peripheral nerves to show that functional improvements are possible after surgery, even in cases where the surgery is performed more than one year after the injury.

\section{MATERIAL and METHODS}

During a 6-year period from 2007 to 2012, we surgically treated a total of 185 patients with peripheral nerve lesions. In this study, we analyzed the results of surgery in 25 patients (a total of 30 nerves) with PNIs, due to penetrating and cutting injuries, who underwent delayed surgical treatment. None of the patients had undergone previous surgery and were examined by our department 3-30 (mean: 11.5) months after the initial injury. In our series, patients were evaluated with respect to pre- and postoperative clinical examinations, electrophysiological studies, lesion type and operative techniques. Muscle strength was assessed according to the MRC scale (British Medical Research Council Scale) (Table I).

Surgical treatment was performed in all cases. Various types of surgical procedures were performed according to the intraoperative findings of injured nerves. Surgical procedures included simple decompression, end-to-end epineural anastomosis, partial excision of a neuroma, end-to-end interfascicular anastomosis and interfascicular anastomosis using sural nerve grafts. Microsurgical techniques were performed for all anastomoses. For the best surgical results, six to nine monofilament sutures were used for nerve repairs after clean re-cutting of the ends of the injured nerves.

If the patient had a complete nerve lesion or multi-fascicled (over 5 fascicles) nerves, and especially if the cut ends showed a very similar fascicular pattern, primary epineural repair was the preferred method of treatment (Figure 1). If there was no transection and the nerves exhibited continuity and less than 5 large fascicles, interfascicular repair was the preferred method of treatment.Nerve grafting was preferred if nerve lesions and a loss of continuity were present and the nerve gap between the proximal and distal stumps was larger than $2 \mathrm{~cm}$.

After surgery, physical therapy and rehabilitation programs were recommended to the patients. The mean follow-up period for the 25 surgically treated patients was 15 months (range, 12-48 months). Postoperative clinical and electrophysiological evaluations similar to those administered in the preoperative period were performed for each patient.

\section{RESULTS}

Age-Gender: The study included 19 (76\%) male and 6 (24\%) female patients. The age of the patients ranged between 16 and 66 years, and the mean age was 30.1 years.

Etiology: The study included patients with penetrating and cutting peripheral nerve injuries. The most common cause of nerve injuries was sharp lacerations resulting from broken glass [68\% of all patients (n: 17)], followed by injuries caused by knives [16\% (n: 4)] other blades [12\% (n: 3)] and circular saw blades [4\% (n: 1)].

Localization and Severity of Lesions: Among 25 cases of nerve injuries, the most frequently wounded nerve was the median nerve $(13,43.3 \%)$, followed by the ulnar $(8,26.6 \%)$, radial $(3,10 \%)$, peroneal $(3,10 \%)$, tibial $(2,6.6 \%)$ and sciatic nerves $(1,3.3 \%)$. Double nerve injuries were detected in our patients. The coexistence of median and ulnar nerve injuries was found in 3 patients, and median and radial (n: 1) and peroneal and tibial (n: 1) nerve injuries were also observed (Table II). According to the EMG findings, total, severe partial and partial lesions were found in 16, 11 and 3 patients, respectively (Table II, III).

Table I: British Medical Research Council Scale for Testing Muscle Strength

\begin{tabular}{ll}
\hline Grade & Testing Muscle Strength \\
\hline M0 & No contraction \\
\hline M1 & Flicker/trace contraction \\
\hline M2 & Active movement with eliminated gravity \\
\hline M3 & Active movement against gravity \\
\hline M4 & Active movement against resistance \\
\hline M5 & Normal/full power \\
\hline
\end{tabular}

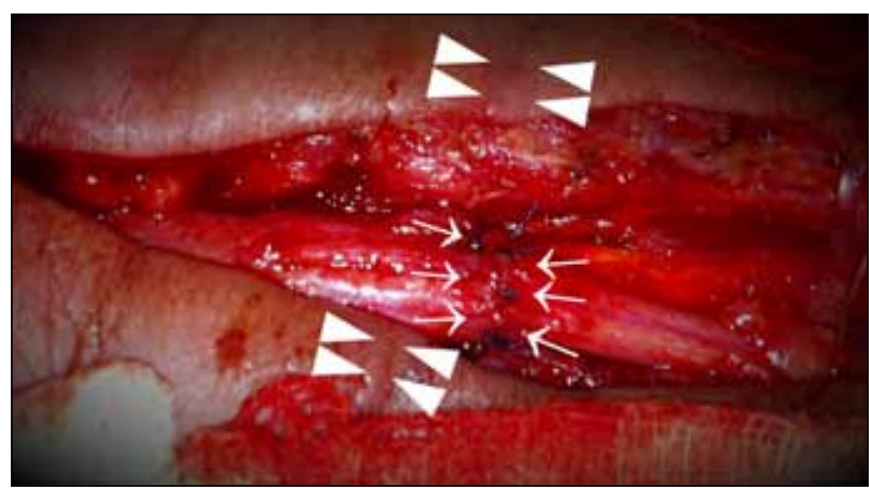

Figure 1: Intraoperative photograph of a left upper extremity showing old scar formation caused by cut injury (arrow heads) and end-to-end epineural repair (arrows). 
Clinical Features: The mean duration from injury to hospital treatment was 11.5 months, ranging from 3 to 30 months. The muscle strength grading scale was used for the clinical evaluation of patients. In 25 patients, the preoperative strength of the muscle, which is linked to the responsible nerve, was M1 in thirteen patients, M2 in twelve patients, and M3 in five patients. M4 and M5 were not found in any patients. The postoperative results of muscle strength tests showed significant functional improvement. The preoperative and postoperative comparisons of the results of muscle strength tests are shown in Figure 2.

Surgical Procedure: Epineural repair was the most often preferred surgical procedure and was performed for 10 (33.3\%) peripheral nerve lesions. External neurolysis and decompression were performed on 8 (26.6\%) lesions, epineurotomy and internal neurolysis were performed on 5 (16.6\%) lesions, interfascicular anastomosis using sural nerve grafting was performed on $4(13.3 \%)$ lesions, and fascicular repair was performed on 3 (\%) lesions (Table II, III). Unfortunately, we could not perform intraoperative neurophysiological monitoring during the surgical procedures. No complications developed in the postoperative period except for a superficial wound infection in one patient.

Outcomes: The mean follow-up period was 18 months (range, 6-36 months). The evaluation of the performed surgical approach, preoperative and postoperative EMG findings and muscle strength scale results are presented in Table III. The preoperative and postoperative comparison of clinical assessments is shown in Figure 3.

According to these results, the greatest improvement was obtained in patients who underwent simple decompression accompanied by external neurolysis and end-to-end epineural anastomosis. Interfascicular anastomosis performed using sural nerve graft was shown to have low probability of surgical success. The most successful EMG findings and clinical improvements were obtained in patients with medial nerve lesions. No significant electrophysiological improvements were observed for radial, tibial and sciatic nerve injuries; however, the results of motor strength assessments did show improvement.

Electrophysiological improvement was not observed in $60.2 \%$ ( $n: 10)$ of 16 injured nerves at the end of a 15-month followup period (Figure 3). Normal postoperative EMG findings were detected in only $10 \%$ (n: 3 ) of all injured nerves. However, the results of muscular strength assessments were better than the EMG findings. According to these results, motor strength classifications of M4 and M5 were detected in $23.4 \%$ (n: 7) of the 30 injured nerves (Figure 2).

\section{DISCUSSION}

Peripheral nerve injuries may cause disability unless treated; therefore, they should be diagnosed as early as possible, and surgical intervention should be performed. A major problem for surgery for peripheral nerve injuries is the unpredictable final outcome. More knowledge regarding the prognostic factors of peripheral nerve surgery is needed for further improvement of functional outcomes after the repair of injured peripheral nerves.

The prognosis of peripheral nerve injuries depends on various factors such as the patient age, type of injury, severity of trauma, delay between the time of injury and repair, presence of additional organ injury and infection, affected nerve, distance between injury level and the affected organ, status of the anatomical integrity of the injured nerve, length of the defect between the proximal and distal ends and the experience and techniques of the surgeon $(3,29,30-32)$. Prognoses are better

Table II: Patterns and Severity of Peripheral Nerve Injury in the 25 Patients and Frequency of Surgical Procedures

\begin{tabular}{|c|c|c|c|c|c|c|c|c|}
\hline & & Median & UInar & Radial & Peroneal & Tibial & Sciatic & Total \\
\hline \multicolumn{9}{|l|}{ Lesion type } \\
\hline & Total & 8 & 4 & 1 & 2 & 1 & - & 16 \\
\hline & Severe Partial & 4 & 3 & 1 & 1 & 1 & 1 & 11 \\
\hline \multicolumn{9}{|l|}{ Surgical procedure } \\
\hline & $\begin{array}{l}\text { External Neurolysis/ } \\
\text { Decompression }\end{array}$ & 3 & 2 & 1 & - & 1 & 1 & 8 \\
\hline & $\begin{array}{l}\text { Epineurotomy/ } \\
\text { Internal Neurolysis }\end{array}$ & 2 & 1 & 1 & 1 & - & - & 5 \\
\hline & $\begin{array}{l}\text { Interfascicular Anastomosis/ } \\
\text { Sural nerve grafting }\end{array}$ & 2 & 1 & - & 1 & - & - & 4 \\
\hline
\end{tabular}


Table III: The Preoperative and Postoperative Outcomes according to Location, Severity of Injury and Surgical Procedures

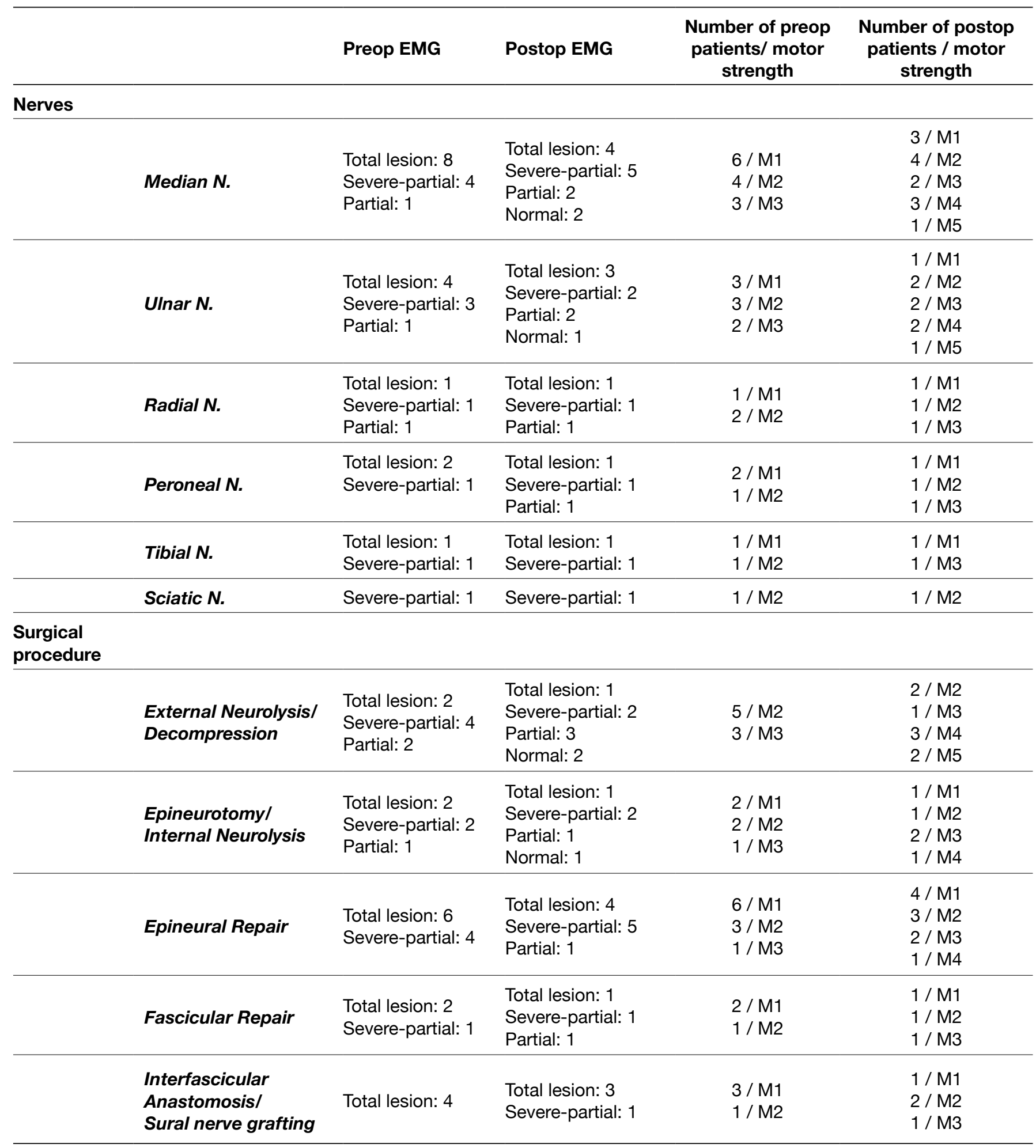




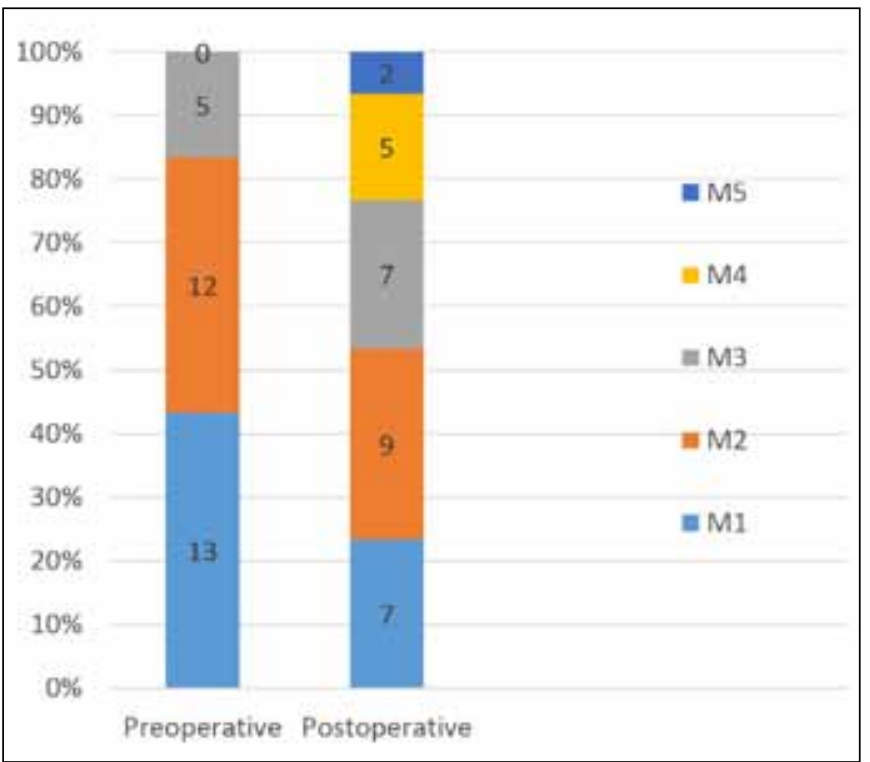

Figure 2: Graphic showing comparison of the preoperative and postoperative clinical outcomes of patients.

in children and young people than older adults $(2,5,25)$. The critical age for a good prognosis ranges from 10 to 54 years $(14,18)$. The mean age of our cases was 30.1 years.

The outcome of nerve repair is dependent on the degree of nerve injury. In patients with peripheral nerve injuries, various repair rates have been reported in the literature based on the evaluation of the degree of nerve injury (total and partial lesions). Noble et al. reported a $25 \%$ rate of repair for total and partial lesions in (24). In our series, the rate of repair for total lesions was $56.1 \%$ for all patients.

Several methods can be used to repair injured nerves. Intraoperative findings play an important role in the selection of surgical techniques. In our series, the most commonly performed interventions were end-to-end epineural anastomosis and external neurolysis accompanied by decompression. The results were more successful in the patients who underwent these surgical procedures. Additionally, the treatment success rate was higher in patients who underwent direct fascicular repair than in those who underwent end-to-end repair.

The length of the defect between the proximal and distal nerve is also an effective predictor of the prognosis $(16,17)$. There is a consensus in the literature that the prognosis after surgical repair becomes worse as nerve defects become larger $(9,14$, $28,29,30)$. Because our study is retrospective, we did not measure defect lengths.

Some previously reported studies have shown that injuries of the ulnar nerve in the upper extremities and the peroneal nerve in the lower extremities present worse prognoses (29, 30). However, we found a good clinical outcome in patients with median and ulnar nerve injuries.

Daneyemez et al reported their 10-year experience with over 1500 patients who suffered peripheral nerve injuries. Their study showed that nerve continuity and non-complete

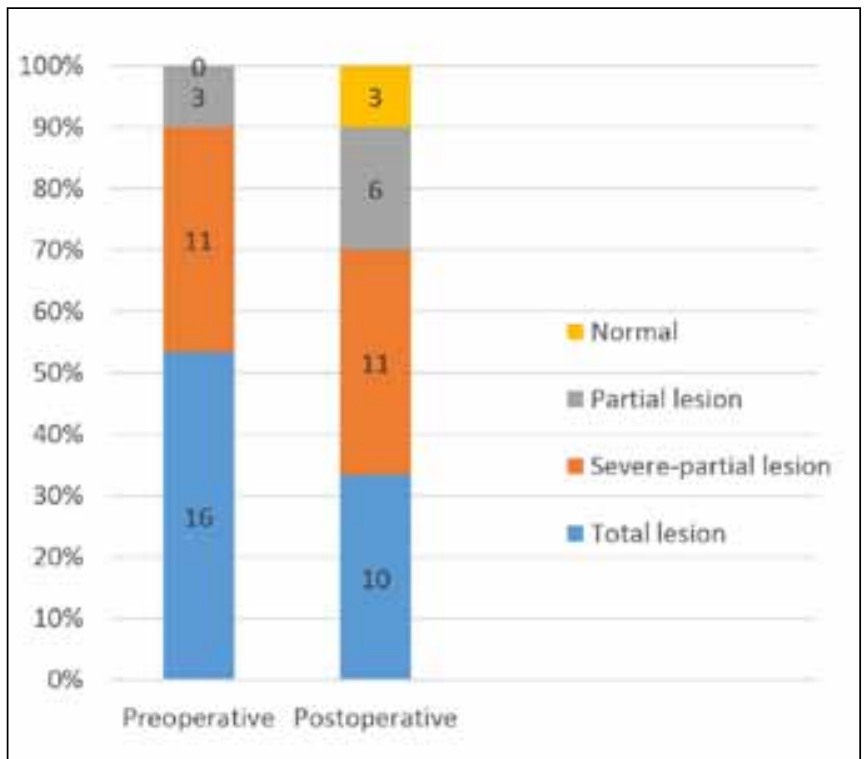

Figure 3: Graphic showing comparison of the preoperative and postoperative electrophysiological findings of patients.

transection were associated with good recovery, whereas, neuroma-in-continuity or complete irregular transections were related to moderate or poor outcomes (8).

There is some degree of disagreement concerning the optimal surgical timing for repairing injured nerves. The timing of nerve repairs is classified as primary repair (within 24 hours), delayed primary repair (within 1 to 7 days) or secondary repair (more than one week after injury) $(5,10)$. In this study, we reported the clinical and electrophysiological results of our patients who underwent secondary repairs of injured peripheral nerves. Both experimental $(6,23)$ and clinical studies $(5,7,10,34)$ have shown that early primary repair is superior to secondary repair as long as the tissue bed is adequate $(14,21,33)$. In recent years, early primary repair has been the more preferred procedure in cases of transection of the nerve trunk related to a clean sharp wound with minimal contamination and no damage to vessels, bone or soft-tissue caused by sharp objects such as glass or blades (7, 10, 19, 24, 34). Primary repair provides some advantages such as earlier return of function and decreased tension on the suture line at the site of repair resulting from stump contraction. Additionally, some studies have recommend nerve repair for blunt lacerations within 2 to 4 weeks after injury to allow the delineation of proximal and distal stump damage $(16,35)$.

It is generally thought that early surgical repair provides the best outcome for patients with peripheral nerve injury, and the prognosis is relatively poor if one year or longer passes before the repair of a nerve lesion $(4,11,12,15)$. However, several studies have indicated that the results of delayed repair can be successful in most cases and recommend late term surgical treatment for peripheral nerve injuries $(13,20,26,27)$.

The use of microsurgical techniques for nerve repair provides good functional improvement. In a study by Rochkinds et al, the postoperative clinical analysis showed a statistically 
significant improvement in motor functional activity, not only in the 33 patients who underwent microsurgical treatment up to one year after injury, but also in the 31 patients who underwent surgery one year or later after the injury (27). Similarly, another study by these authors showed the outcomes of 35 patients suffering from old peripheral nerve injuries (from 1,2 to 50 years after injury). A good functional outcome was observed in $57 \%$ of 35 patients with old peripheral nerve injuries (26).

In our series, EMG follow-up after surgery demonstrated apparent electrophysiological improvement. EMG findings showed a return to normal function in $10 \%$ of the patients. The motor strength of nerve-related muscles in patients improved postoperatively to classifications of M4 (16.7\%) and M5 (6.7\%).

Our study has some deficiencies and limitations, such as the low number of patients and the retrospective, single center design. The number of patients was limited to 25 in our study. Therefore, controlled, prospective and randomized studies with larger case series are necessary to evaluate our findings. In addition, we did not perform electrophysiological monitoring during surgery. Intraoperative electrophysiological monitoring could provide an opportunity to assess the functional integrity of susceptible neural elements during surgery.

\section{- CONCLUSION}

Early primary repair should primarily be performed for nerve lesions in most patients. However, late surgical interventions can be performed in carefully selected groups of patients who do not promptly receive care for various reasons, although the results in these patients are worse than those in patients who are treated earlier.

\section{REFERENCES}

1. Adeyemi-Doro HO: Pattern of peripheral traumatic neuropathy of the upper limb in Lagos. Injury 19: 329-332, 1988

2. Allan $\mathrm{CH}$ : Functional results of primary nerve repair. Hand Clin 16 : 67-72, 2000

3. Barrios $\mathrm{C}$, Amillo $\mathrm{S}$, de Pablos $\mathrm{J}$, Cañadell J: Secondary repair of ulnar nerve injury. 44 cases followed for 2 years. Acta Orthop Scand 61: 46-49, 1990

4. Barrios C, de Pablos J: Surgical management of nerve injuries of the upper extremity in children: A 15-year survey. J Pediatr Orthop 11: 641-645, 1991

5. Birch R, Raji AR: Repair of median and ulnar nerves. Primary suture is best. J Bone Joint Surg Br 73: 154-157, 1991

6. Bolesta MJ, Garrett WE Jr, Ribbeck BM, Glisson RR, Seaber AV, Goldner JL: Immediate and delayed neurorrhaphy in a rabbit model: A functional, histologic, and biochemical comparison. $J$ Hand Surg Am 13: 352-357, 1988

7. Dahlin LB: Techniques of peripheral nerve repair. Scand J Surg 97: 310-316, 2008

8. Daneyemez M, Solmaz I, Izci Y: Prognostic factors for the surgical management of peripheral nerve lesions. Tohoku J Exp Med 205: 269-275, 2005
9. Donzelli R, Benvenuti D, Schonauer C, Mariniello G, De Divitiis E: Microsurgical nervous reconstruction using autografts: A twoyear follow-up. J Neurosurg Sci 42:79-83, 1998

10. Ertem K, Denizhan Y, Yoloğlu S, Bora A: The effect of injury level, associated injuries, the type of nerve repair, and age on the prognosis of patients with median and ulnar nerve injuries. Acta Orthop Traumatol Turc 39: 322-327, 2005

11. Garozzo D, Ferraresi S, Buffatti P: Surgical treatment of common peroneal nerve injuries: Indications and results. A series of 62 cases. J Neurosurg Sci 48:105-112, 2004

12. Gosk J, Rutowski R, Rabczyński J: The lower extremity nerve injuries-own experience in surgical treatment. Folia Neuropathol 43: 148-152, 2005

13. Hattrup SJ, Wood MB: Delayed neural reconstruction in the lower extremity: Results of interfascicular nerve grafting. Foot Ankle 7: 105-109, 1986

14. Kallio PK, Vastamäki M: An analysis of the results of late reconstruction of 132 median nerves. J Hand Surg Br 18: 97-105, 1993

15. Kim DH, Kline DG: Management and results of peroneal nerve lesions. Neurosurgery 39: 312-319, 1996

16. Kim DH, Murovic JA, Tiel RL, Kline DG: Management and outcomes in 318 operative common peroneal nerve lesions at the Louisiana State University Health Sciences Center. Neurosurgery 54: 1421-1428, 2004

17. Kline DG: Nerve surgery as it is now and as it may be. Neurosurgery 46: 1285-1293, 2000

18. Koller R, Rath T, Benditte-Klepetko H, Eberhard D, Millesi $\mathrm{H}$ : Results of restoration of continuity in peripheral nerves in childhood and adolescence. Handchir Mikrochir Plast Chir 30: 109-115, 1998

19. Kuran I, Özcan H, Kuran B, Aydın H: The surgical approach to peripheral nerve repair. Acta Orthop Traumatol Turc 29:37-40, 1995

20. Lusskin R, Battista A, Lenzo S, Price A: Surgical management of late post-traumatic and ischemic neuropathies involving the lower extremities: Classification and results of therapy. Foot Ankle 7: 95-104, 1986

21. Mackinnon SE: New directions in peripheral nerve surgery. Review. Ann Plast Surg 22: 257-273,1989

22. McAllister RM, Gilbert SE, Calder JS, Smith PJ: The epidemiology and management of upper limb peripheral nerve injuries in modern practice. J Hand Surg Br 21: 4-13, 1996

23. Millesi $\mathrm{H}$ : Peripheral nerve repair: Terminology, questions, and facts. J Reconstr Microsurg 2: 21-31, 1985

24. Noble J, Munro CA, Prasad VS, Midha R: Analysis of upper and lower extremity peripheral nerve injuries in a population of patients with multipl injuries. J Trauma 45: 116-122, 1998

25. Ozdemir HM, Biber E, Oğün T: The results of nerve repair in combined nerve-tendon injuries of the forearm. Ulus Travma Acil Cerrahi Derg 10: 51-56, 2004

26. Rochkind S, Alon M: Microsurgical management of old injuries of the peripheral nerve and brachial plexus. J Reconstr Microsurg 16: 541-546, 2000

27. Rochkind S, Filmar G, Kluger Y, Alon M: Microsurgical management of penetrating peripheral nerve injuries: Pre, intraand postoperative analysis and results. Acta Neurochir Suppl 100: 21-24, 2007 
28. Roganovic Z: Missile-caused median nerve injuries: Results of 81 repairs. Surg Neurol 63: 410-418, 2005

29. Secer HI, Daneyemez M, Gonul E, Izci Y: Surgical repair of ulnar nerve lesions caused by gunshot and shrapnel: Results in 407 lesions. J Neurosurg 107: 776-783, 2007

30. Secer HI, Daneyemez M, Tehli O, Gonul E, Izci Y: The clinical, electrophysiologic, and surgical characteristics of peripheral nerve injuries caused by gunshot wounds in adults: A 40-year experience. Surg Neurol 69: 143-152, 2008

31. Taylor CA, Braza D, Rice JB, Dillingham T: The incidence of peripheral nerve injury in extremity trauma. Am J Phys Med Rehabil 87: 381-385, 2008
32. Uzun N, Tanriverdi T, Savrun FK, Kiziltan ME, Sahin R, Hanimoglu $\mathrm{H}$, Hanci M: Traumatic peripheral nerve injuries: Demographic and electrophysiologic findings of 802 patients from a developing country. J Clin Neuromuscul Dis 7: 97-103, 2006

33. Vastamäki M, Kallio PK, Solonen KA: The results of secondary microsurgical repair of ulnar nerve injury. J Hand Surg Br 18: 323326, 1993

34. Walsh S, Midha R: Use of stem cells to augment nerve injury repair. Neurosurgery 65: A80-86, 2009

35. Yegiyants S, Dayicioglu D, Kardashian G, Panthaki ZJ: Traumatic peripheral nerve injury: A wartime review. J Craniofac Surg 21: 998-1001, 2010 